\title{
The association between urbanization and reduced renal function: findings from the China Health and Nutrition Survey
}

\author{
Yosuke Inoue ${ }^{1 *}$, Annie Green Howard ${ }^{1,2}$, Amanda L. Thompson 1,3,4, Michelle A. Mendez ${ }^{1,4}$, Amy H. Herring ${ }^{1,2}$ \\ and Penny Gordon-Larsen ${ }^{1,4}$
}

\begin{abstract}
Background: While chronic kidney disease (CKD) is a growing public health concern in low- and middle-income countries, such as China, few studies have investigated the association between urbanization and the occurrence of CKD in those countries.

Methods: We investigated the association between urbanization and estimated glomerular filtration rate (eGFR), an important CKD risk marker. Data came from the China Health and Nutrition Survey wave 2009, in which we collected fasting serum, individual and household data along with community level urbanization data, which was used to derive a study-specific urbanization measure, in 218 communities across nine provinces. A total of 3644 men and 4154 women participants aged 18 years or older were included in the analysis. Reduced renal function was defined as eGFR of less than $60 \mathrm{~mL} / \mathrm{min} / 1.73 \mathrm{~m}^{2}$ measured using serum creatinine concentration (mg/dL).

Results: After adjusting for socio-demographic (e.g., age, education and household income), a sex-stratified multilevel logistic model revealed that living in a more urbanized community was associated with higher odds of reduced eGFR (odds ratio $[\mathrm{OR}]=1.38$ per one-standard deviation $[\mathrm{SD}]$ increase in the CHNS specific urbanization index, 95\% confidence interval $[\mathrm{Cl}]=1.11-1.73$ for men; $\mathrm{OR}=1.35,95 \% \mathrm{Cl}=1.11-1.62$ for women). After adjusting for behavioral variables (i.e., alcohol consumption, smoking, physical activity and diet), as well as obesity and cardiometabolic risk factors, the association was attenuated in men $(\mathrm{OR}=1.25,95 \% \mathrm{Cl}=0.98-1.59)$, but remained statistically significant in women $(\mathrm{OR}=1.24,95 \% \mathrm{Cl}=1.01-1.52)$.
\end{abstract}

Conclusion: Our findings suggest that living in an urban environment is linked with higher odds of reduced renal function independently of behavioral and cardiometabolic risk factors, which have been shown to increase along with urbanization.

Keywords: Glomerular filtration rate, Creatinine, Renal insufficiency, China, Urbanization

\section{Background}

Chronic kidney disease (CKD) is an important risk factor for end-stage renal disease [1], all-cause and cardiovascular mortality [2], and non-vascular outcomes (e.g., cognitive decline and functional impairment $[3,4])$. Lozano et al. [5] reported an increase in CKD of 15\% between 1990 and 2010 across the globe. Individuals in low- and middleincome countries were disproportionally affected [6] perhaps due to increases in non-communicable disease and

\footnotetext{
* Correspondence: inoyo@live.unc.edu

${ }^{1}$ Carolina Population Center, The University of North Carolina at Chapel Hill,

Chapel Hill, NC 27516, USA

Full list of author information is available at the end of the article
}

exposure to environmental toxins along with urbanization [7]. In addition, older age [3, 8-14], being a woman [3, 8, $10,11,14,15]$, having metabolic syndromes $[3,8-14,16-$ 18], smoking [9, 10,17-19] or lower socioeconomic status (SES) $[3,20]$ have been shown to be associated with development and progression of CKD.

Despite the potential influence on some of the abovementioned CKD risk factors, relatively few studies have examined community context in relation to the development of CKD. In the USA and the UK, living in a low SES community has been linked with higher risk of CKD [21, 22]. In developing countries, on the other hand, there have been conflicting results. For example, 
Wang et al. [23] showed that CKD prevalence was higher in urban areas (where SES was higher on average) compared with rural areas. Using Chinese data in 2011 to 2012. Conversely, Zhang et al. [14] showed no statistically significant difference between urban and rural residents in China in 2009 to 2010 and Kaze et al. [12] reported that the prevalence of CKD was higher in rural areas compared to in urban areas in Cameroon.

As renal replacement therapy is not always available to CKD patients in developing countries where economic and medical resources are scant [7, 24], there is an urgent need to identify those at higher risk of CKD at an earlier stage. It is also critical to identify correlates of CKD that could be candidates for preventive efforts, while distinguishing the contribution attributed to individual behavioral risk factors versus community-level factors, which may require different intervention strategies. For example, discrepant findings for CKD in rural versus urban areas may relate to use of a conventional dichotomous administrative classification of urban versus rural. Yet, urbanization captures several nuanced aspects of the community environment [25]. Second, few studies have used multilevel models to estimate contextual effects (i.e., residents in the same community tend to experience a similar exposure and health status [26]). Third, few studies have investigated the role of diet and physical activity behaviors in relation to the association between urbanization and CKD in developing countries.

To address these gaps, we used a validated urbanization index assessed at community level and estimated glomerular filtration rate (eGFR) to investigate the association between urbanization and reduced renal function in China. We used data from the China Health and Nutrition Survey (CHNS) and employed a multilevel model controlling for socio-demographic (i.e., age, education and household income) and behavioral variables (i.e., alcohol consumption, smoking, physical activity and diet), body mass index (BMI) and cardio-metabolic factors (i.e., blood pressure, hemoglobin A1c, fasting blood glucose and low-density lipoprotein) to examine the association between urbanization and CKD.

\section{Methods}

\section{China Health and Nutrition Survey}

The CHNS is an ongoing longitudinal study which collected data from 228 communities across nine provinces (i.e., Heilongjiang, Liaoning, Shandong, Henan, Jiangsu, Hunan, Hubei, Guangxi, and Guizhou). Multistage random-cluster design and a stratified probability sample were used to select counties and cities stratified by income using State Statistical Office definitions [27]; we then selected participating communities and households from these strata. The cohort mirrored national profiles in relation to age, sex and education initially [28-30] and the provinces in the CHNS sample comprised $44 \%$ of the population in China as of 2009. Details on the CHNS procedures have been described previously [31].

Fasting blood was available in wave 2009 data to generate serum creatinine data for 9493 participants aged 18 years or older. After excluding those who did not have information on age $(n=5)$, education $(n=54)$, household income $(n=133)$, health-related behaviors $(n=1303)$ and the other biomarkers $(n=200)$, we have an analytic sample of 7798 participants (3644 men and 4154 women) living in 218 communities.

\section{Dependent variable}

Using fasting serum to derive serum creatinine concentration (Scr, mg/dL), we calculated estimated glomerular filtration rates (eGFR), using the following set of equations [32] which were modified based on the Chronic Kidney Disease-Epidemiology (CKD-EPI) equations and acquired the best performance among serum creatininebased equations validated among Chinese population in Ye et al. [33]. Reduced renal function was defined as eGFR of $<60 \mathrm{~mL} / \mathrm{min} / 1.73 \mathrm{~m}^{2}$ [34].

\section{Explanatory variables}

\begin{tabular}{lll}
\hline Woman & $\mathrm{Scr} \leq 7 \mathrm{mg} / \mathrm{dL}$ & $144 \times(\mathrm{Scr} / 0.7)^{0.156} \times 0.993^{\text {age}} ;$ \\
& $\mathrm{Scr}>7 \mathrm{mg} / \mathrm{dL}$ & $144 \times(\mathrm{Scr} / 0.7)^{-1.057} \times 0.993^{\text {age }} ;$ \\
Man & $\mathrm{Scr} \leq 9 \mathrm{mg} / \mathrm{dL}$ & $141 \times(\mathrm{Scr} / 0.9)^{0.074} \times 0.993^{\text {age }} ;$ \\
& $\mathrm{Scr}>9 \mathrm{mg} / \mathrm{dL}$ & $141 \times(\mathrm{Scr} / 0.9)^{-1.057} \times 0.993^{\text {age }}$ \\
\hline
\end{tabular}

We used a 12-component study-specific urbanization index, which was previously validated to capture the degree of urbanization in the study communities (reliability across study waves [Cronbach's Alpha]: 0.85-0.89; validity [correlation with official classification]; 0.75-0.78) [25]. The following 12 components were included in the development of the urbanization index: (1) population density; (2) types of economic activity; (3) traditional market; (4) modern markets; (5) transportation and infrastructure; (6) sanitation; (7) communications (e.g., TV, mobile, post, and cinema); (8) housing (e.g., electricity, indoor tap water, and flush toilet); (9) education; (10) diversity (i.e., variation in community education level and variation in community income level); (11) health infrastructure; and (12) social services. The scale has a possible range of $0-120$, with a higher score reflecting more urban characteristics across these twelve multiple domains.

Sociodemographic and behavior data obtained using the CHNS questionnaire included age (in years), sex (men and women), education (graduated from primary school or less; graduated from junior high school; graduated from high school; and attained further education), 
annual household income per capita tertiles (0-6533 yuan [low]; 6542-13,859 yuan [middle]; and 13,862378,571 yuan [high]), health-related behaviors such as alcohol ( $</ \geq$ once per month), current smoking (yes, no), and weekly physical activity level derived from a detailed seven-day PA recall across a variety of domains. We also used diet data derived from three consecutive 24-h dietary recalls with energy and nutrient content of foods estimated based on a Chinese food composition table [35]. This dietary assessment has been validated relative to doubly labeled water for energy (r: 0.56 [men] and 0.60 [women]) [36] and urine for sodium ( $r$ : 0.58) and potassium ( $r: 0.59$ ) [37]. We included protein consumption and energy intake and checked changes in the results by including either sodium intake and potassium intake or sodium-to-potassium ratio. To investigate the impact of non-communicable diseases as potential mediators linking urbanization and CKD, we used anthropometric data to classify overweight and obesity (overweight: body mass index [BMI; $\mathrm{kg} / \mathrm{m}^{2}$ ]: $24.0-27.99$; obesity: $\mathrm{BMI} \geq 28.0$ [38]) and hypertension (either systolic pressure $\geq 140 \mathrm{mmHg}$, diastolic pressure $\geq 90 \mathrm{mmHg}$ or self-reported antihypertensive medication [39]) and fasting blood used to classify diabetes mellitus (DM) (either hemoglobin A1c $\geq 6.5 \%$ or fasting blood glucose $\geq 126 \mathrm{mg} / \mathrm{dL}$ or self-reported diagnosis of DM [39]) and high concentration of low-density lipoprotein cholesterol (LDL; $\geq 130 \mathrm{mg} / \mathrm{dL}$ [39]).

\section{Statistical analyses}

Descriptive characteristics of the study participants were compared by eGFR status (i.e., $</ \geq 60 \mathrm{~mL} / \mathrm{min} /$ $1.73 \mathrm{~m}^{2}$ ) using either t-tests (for continuous variables) or $x^{2}$ tests (for categorical variables) in each sex. A sexstratified multilevel model was used to investigate the association between the community-level urbanization index and reduced renal function while accounting for multiple individuals within a community with a random intercept for individual. We used several steps for adjustment; specifically, the initial model included age, sex, educational attainment and household income (Model 1). Then we added health-related behaviors: frequency of alcohol consumption $(</ \geq$ once per month), current smoking (men only due to small numbers of women smokers) (yes, no), physical activity (per 10 metabolic equivalents [METs]), energy intake (per $1000 \mathrm{kcal}$ ), protein intake (per $100 \mathrm{~g}$ ), sodium intake and potassium intake in Model 2 or sodium-topotassium ratio in Model 3. We then fuether adjusted Model 2 for BMI and cardiometabolic risk factors (hypertension, DM, and high LDL cholesterol) in Model 4. Overweight and obesity were combined due to small sample sizes.
In addition, to better understand the pathways linking urbanization and reduced renal function, we additionally conducted a separate analysis in which we incorporated the 12 components of the urbanization index in the model while adjusting for the covariates included in Model 4 and also stratifying by sex.

All statistical analyses were conducted using Stata 14.0 (College Station, TX). The level of statistical significance (two-tailed) was set at $p<0.05$.

\section{Results}

Table 1 shows the basic characteristics of the study participants. The prevalence of reduced renal function was 8.1\% (6.4\% for men and $9.6 \%$ for women). Those with reduced renal function tended to be considerably older than those without (71.5 years vs 49.6 years, $p<0.001$ for men; 69.4 years vs. 49.0 years, $p<0.001$ for women), were more likely to have a lower educational attainment (i.e., graduation from primary school or less; $54.5 \%$ vs. $33.1 \%, p<0.001$ for men; $80.7 \%$ vs. $49.0 \%, p<0.001$ for women), and were more likely to have low household income (33.5\% vs. $31.9 \%, p=0.049$ for men; $38.1 \%$ vs. $34.2 \%, p<0.001$ for women). In terms of numerous health-related behaviors, individuals with reduced renal function differed significantly from others with markedly lower levels of alcohol consumption (among men; $p<0.001$ ), smoking (among men; $p<0.001$ ), physical activity $(p<0.001)$, energy intake $(p<0.001)$, protein intake $(p<0.001)$, sodium intake $(p=0.009$ for men; $p=0.004$ for women), and potassium intake $(p<0.001)$. Furthermore, those with reduced renal function were more likely to have hypertension $(64.4 \%$ vs $31.6 \%$, $p<0.001$ for men; $56.4 \%$ vs. $25.9, p<0.001$ for women), DM $(21.0 \%$ vs. $11.5 \%, p<0.001$ for men and $25.8 \%$ vs. $8.6 \%, p<0.001$ for women), and high LDL cholesterol (only among women; $52.4 \%$ vs. $31.0 \%, p<0.001$ ). Those who lived in more urbanized communities tend to be older, more educated, and richer, consume more protein, be more hypertensive while they consumed less alcohol, smoked less, exercised less and consumed less energy. There were no rural-urban gradients in relation to potassium intake, sodium-to-potassium ratio, obesity, diabetes and high LDL (Additional file 1: Table S1).

Table 2 shows the results of a multilevel logistic regression analysis in men. In Model 1, urbanization was positively associated with the odds of reduced renal function. Specifically, a one-standard deviation increase in the urbanization index (i.e., 19.5) was associated with a 1.38 times higher odds of reduced renal function $(95 \%$ $\mathrm{CI}=1.11-1.73)$. An additional adjustment for behavioral variables in Model 2 attenuated the association between urbanization and reduced renal function, but the association remained statistically significant $(\mathrm{OR}=1.27,95 \%$ $\mathrm{CI}=1.00-1.61)$. Alcohol consumption $(\mathrm{OR}=0.54,95 \%$ 
Table 1 Basic characteristics of the study participants in China Health and Nutrition Survey (2009), stratified by sex and estimated glomerular filtration rate

\begin{tabular}{|c|c|c|c|c|c|c|c|c|c|c|}
\hline \multirow[b]{3}{*}{ Age (in years), mean [SD] } & \multicolumn{5}{|c|}{ Men $(n=3644)$} & \multicolumn{5}{|c|}{ Women $(n=4154)$} \\
\hline & \multicolumn{2}{|c|}{$\begin{array}{l}\text { eGFR } \geq 60 \\
(n=3411)\end{array}$} & \multicolumn{2}{|c|}{$\begin{array}{l}\text { eGFR <60 } \\
(n=233)\end{array}$} & \multirow{2}{*}{$\begin{array}{c}p \text {-value } \\
<0.001\end{array}$} & \multicolumn{2}{|c|}{$\begin{array}{l}\text { eGFR } \geq 60 \\
(n=3755)\end{array}$} & \multicolumn{2}{|c|}{$\begin{array}{l}\text { eGFR <60 } \\
(n=399)\end{array}$} & \multirow{2}{*}{$\begin{array}{c}p \text {-value } \\
<0.001\end{array}$} \\
\hline & 49.6 & 14.4 & 71.5 & 9.7 & & 49.0 & 13.7 & 69.4 & 10.7 & \\
\hline \multicolumn{11}{|l|}{ Education, n (\%) } \\
\hline Primary school or less & 1130 & 33.1 & 127 & 54.5 & \multirow[t]{4}{*}{$<0.001$} & 1838 & 49.0 & 322 & 80.7 & \multirow[t]{4}{*}{$<0.001$} \\
\hline Junior high school & 1327 & 38.9 & 53 & 22.8 & & 1142 & 30.4 & 44 & 11.0 & \\
\hline Senior high school & 482 & 14.1 & 16 & 6.9 & & 383 & 10.2 & 12 & 3.0 & \\
\hline Post-secondary education & 472 & 13.8 & 37 & 15.9 & & 392 & 10.4 & 21 & 5.3 & \\
\hline \multicolumn{11}{|l|}{ Household income (yuan), n (\%) } \\
\hline Low (0-6533) & 1087 & 31.9 & 78 & 33.5 & \multirow[t]{3}{*}{0.049} & 1284 & 34.2 & 152 & 38.1 & \multirow[t]{3}{*}{0.280} \\
\hline Middle $(6542-13,859)$ & 1164 & 34.1 & 62 & 26.6 & & 1250 & 33.3 & 122 & 30.6 & \\
\hline High $(13,862-378,571)$ & 1160 & 34.0 & 93 & 39.9 & & 1221 & 32.5 & 125 & 31.3 & \\
\hline \multicolumn{11}{|l|}{ Health-related behaviors } \\
\hline Alcohol consumption frequency, n (\%) & 1883 & 55.2 & 67 & 28.8 & $<0.001$ & 223 & 5.9 & 20 & 5.0 & 0.454 \\
\hline Current Smoking, n (\%) & 1923 & 56.4 & 89 & 38.2 & $<0.001$ & 136 & 3.6 & 26 & 6.5 & 0.005 \\
\hline Weekly physical activity (METs), mean [SD] & 224.1 & 216.7 & 81.0 & 119.6 & $<0.001$ & 229.6 & 215.9 & 110.8 & 137.7 & $<0.001$ \\
\hline Energy intake (kcal), mean [SD] & 2335.5 & 600.3 & 2048.7 & 577.0 & $<0.001$ & 1996.0 & 545.9 & 1793.9 & 518.3 & $<0.001$ \\
\hline Protein intake (g), mean [SD] & 71.7 & 22.5 & 62.5 & 20.0 & $<0.001$ & 61.9 & 20.3 & 55.1 & 19.2 & $<0.001$ \\
\hline Sodium intake (g), mean [SD] & 4.9 & 2.6 & 4.4 & 2.6 & 0.009 & 4.6 & 2.6 & 4.2 & 2.4 & 0.004 \\
\hline Potassium intake (g), mean [SD] & 1.7 & 0.6 & 1.5 & 0.6 & $<0.001$ & 1.6 & 0.6 & 1.4 & 0.5 & $<0.001$ \\
\hline Sodium-to-potassium ratio, mean [SD] & 3.0 & 1.9 & 3.2 & 2.2 & 0.266 & 3.1 & 2.1 & 3.3 & 2.1 & 0.122 \\
\hline \multicolumn{11}{|l|}{ Cardiometabolic risk factors } \\
\hline \multicolumn{11}{|l|}{ BMI, n (\%) } \\
\hline$<24.0$ & 2028 & 59.5 & 147 & 63.1 & \multirow[t]{3}{*}{0.547} & 2254 & 60.0 & 238 & 59.7 & \multirow[t]{3}{*}{0.245} \\
\hline $24.0-27.99$ & 1087 & 31.9 & 68 & 29.2 & & 1108 & 29.5 & 109 & 27.3 & \\
\hline$\geq 28.0$ & 296 & 8.7 & 18 & 7.7 & & 393 & 10.5 & 52 & 13.0 & \\
\hline Hypertension, n (\%) & 1078 & 31.6 & 150 & 64.4 & $<0.001$ & 971 & 25.9 & 225 & 56.4 & $<0.001$ \\
\hline Diabetes mellitus, n (\%) & 392 & 11.5 & 49 & 21.0 & $<0.001$ & 324 & 8.6 & 103 & 25.8 & $<0.001$ \\
\hline High LDL, n (\%) & 938 & 27.5 & 77 & 33.1 & 0.068 & 1164 & 31.0 & 209 & 52.4 & $<0.001$ \\
\hline Urbanization index, mean [SD] & 66.3 & 19.4 & 73.6 & 19.7 & $<0.001$ & 66.7 & 19.4 & 72.0 & 19.2 & $<0.001$ \\
\hline eGFR, mean $[S D]$ & 83.8 & 18.6 & 50.7 & 9.9 & - & 84.5 & 13.4 & 54.1 & 9.3 & - \\
\hline
\end{tabular}

${ }^{a}$ Characteristics of the participants were compared using t-test for continuous variables and $x^{2}$ test for categorical variables

$\mathrm{CI}=0.37-0.77)$ and weekly physical activity level $(\mathrm{OR}=0.99,95 \% \mathrm{CI}=0.97-1.00)$ were each inversely associated with reduced renal function; these associations observed in Model 2 did not change when sodium and potassium intakes were replaced with sodium-to-potassium ratio in Model 3. After adjusting for BMI and the cardiometabolic risk factors (Model 4), the association between urbanization and reduced renal function were attenuated $(\mathrm{OR}=1.25,95 \% \mathrm{CI}=0.98-1.59)$ and hypertension $(\mathrm{OR}=1.93,95 \% \mathrm{CI}=1.35-2.74)$ was shown to be positively associated with reduced renal function.

Table 3 shows the results of a multilevel logistic regression analysis in women. Urbanization was significantly associated with reduced renal function in all models (e.g., $\mathrm{OR}=1.24,95 \% \mathrm{CI}=1.01-1.52$ in Model 4). In Models 2 and 4, there was an inverse relationship between potassium intake and reduced renal function (e.g., $\mathrm{OR}=0.64$, 95\% CI $=0.44-0.92$ in Model 2). The cardiometabolic risk factors investigated in this study were positively associated with reduced renal function; specifically hypertension $(\mathrm{OR}=1.34,95 \% \mathrm{CI}=1.01-1.78)$, diabetes mellitus $(\mathrm{OR}=2.07,95 \% \mathrm{CI}=1.47-2.92)$, and high low-density lipoprotein $(\mathrm{OR}=1.42,95 \% \mathrm{CI}=1.09-1.87)$ were associated with reduced renal function.

Table 4 shows the results of multilevel logistic regression analyses using the 12 components of the urbanization 
Table 2 Results of a multilevel logistic model to investigate the association between urbanization and reduced renal function among Chinese men (2009)

\begin{tabular}{|c|c|c|c|c|c|c|c|c|c|c|c|c|}
\hline & \multicolumn{3}{|c|}{ Model 1} & \multicolumn{3}{|c|}{ Model 2} & \multicolumn{3}{|c|}{ Model 3} & \multicolumn{3}{|c|}{ Model 4} \\
\hline & OR & $95 \% \mathrm{Cl}$ & $p$-value & OR & $95 \% \mathrm{Cl}$ & $p$-value & OR & $95 \% \mathrm{Cl}$ & $p$-value & OR & $95 \% \mathrm{Cl}$ & $p$-value \\
\hline Urbanization $^{\mathrm{a}}$ & 1.38 & $1.11,1.73$ & 0.004 & 1.27 & $1.00,1.61$ & 0.048 & 1.28 & $1.01,1.62$ & 0.042 & 1.25 & $0.98,1.59$ & 0.074 \\
\hline \multicolumn{13}{|l|}{ Health-related behavior } \\
\hline Alcohol consumption ${ }^{\mathrm{b}}$ & & & & 0.54 & $0.37,0.77$ & 0.001 & 0.53 & $0.37,0.76$ & 0.001 & 0.52 & $0.36,0.75$ & $<0.001$ \\
\hline Smoking ${ }^{c}$ & & & & 0.86 & $0.60,1.22$ & 0.395 & 0.87 & $0.61,1.23$ & 0.420 & 0.90 & $0.63,1.30$ & 0.585 \\
\hline Total physical activity ${ }^{d}$ & & & & 0.99 & $0.97,1.00$ & 0.043 & 0.99 & $0.97,1.00$ & 0.041 & 0.99 & $0.98,1.00$ & 0.084 \\
\hline Energy intake ${ }^{e}$ & & & & 1.29 & $0.83,2.00$ & 0.251 & 1.18 & $0.77,1.82$ & 0.440 & 1.26 & $0.81,1.97$ & 0.308 \\
\hline Protein intake ${ }^{f}$ & & & & 0.95 & $0.24,3.73$ & 0.940 & 0.47 & $0.14,1.60$ & 0.228 & 0.81 & $0.20,3.24$ & 0.760 \\
\hline Sodium intake & & & & 0.95 & $0.89,1.03$ & 0.199 & & & & 0.95 & $0.88,1.02$ & 0.157 \\
\hline Potassium intake & & & & 0.70 & $0.45,1.08$ & 0.111 & & & & 0.72 & $0.46,1.12$ & 0.148 \\
\hline Sodium-to-potassium ratio & & & & & & & 0.96 & $0.88,1.05$ & 0.407 & & & \\
\hline \multicolumn{13}{|l|}{ Cardiometabolic risk factors } \\
\hline Overweight/Obesity ${ }^{9}$ & & & & & & & & & & 1.03 & $0.71,1.50$ & 0.858 \\
\hline Hypertension $^{\mathrm{h}}$ & & & & & & & & & & 1.93 & $1.35,2.74$ & $<0.001$ \\
\hline Diabetes Mellitus'i & & & & & & & & & & 1.36 & $0.88,2.11$ & 0.162 \\
\hline High LDL ${ }^{j}$ & & & & & & & & & & 1.17 & $0.80,1.69$ & 0.419 \\
\hline
\end{tabular}

Models were adjusted for age (in years), educational attainment (primary education or less, junior high school, high school and attained further education) and household income (low, middle and high)

${ }^{a}$ Results are expressed per one-SD increase

${ }^{\mathrm{b}}$ The referent was those who drank less than once per month

'The referent was those who didn't smoke

${ }^{\mathrm{d}}$ Results are expressed per 10 METs increase

${ }^{\mathrm{e}}$ Results are expressed per $1000 \mathrm{kcal}$ increase

${ }^{f}$ Results are expressed per $100 \mathrm{~g}$ increase

${ }^{9}$ The referent was those whose body mass index was 24.0 or less

${ }^{h}$ Hypertension was defined by either systolic pressure $\geq 140 \mathrm{mmHg}$, diastolic pressure $\geq 90 \mathrm{mmHg}$ or self-reported antihypertensive medication

'Diabetes were defined by either hemoglobin A1c $\geq 6.5 \%$ or fasting blood glucose $\geq 126 \mathrm{mg} / \mathrm{dL}$ or self-reported diagnosis of DM

${ }^{\mathrm{j}}$ Higher LDL was defined by $\mathrm{LDL} \geq 130 \mathrm{mg} / \mathrm{dL}$

index as explanatory variables. Among both sexes, the housing component was positively associated with higher odds of reduced renal function (men: $\mathrm{OR}=1.51,95 \%$ $\mathrm{CI}=1.01-2.28$; women: $\mathrm{OR}=1.39,95 \% \mathrm{CI}=1.01-1.93)$. In addition, among women, the traditional market component was also positively associated with reduced renal function $(\mathrm{OR}=1.27,95 \% \mathrm{CI}=1.01-1.58)$ while communication component $(\mathrm{OR}=0.75,95 \% \mathrm{CI}=0.59-0.95)$ and health component $(\mathrm{OR}=0.80,95 \% \mathrm{CI}=0.66-0.98)$ were rather inversely associated with reduced renal function.

\section{Discussion}

\section{Findings of this study}

The prevalence of reduced renal function was $8.1 \%$ among CHNS participants aged 18 to 94 years of age. Furthermore, using a validated, multicomponent urbanization index, we found a positive association between urbanization and reduced renal function in the CHNS. Specifically, a onestandard deviation increase in the urbanization index was associated with a $1.38(95 \% \mathrm{CI}=1.11-1.73)$ and $1.35(95 \%$ $\mathrm{CI}=1.11-1.62)$ times higher odds of reduced renal function among men and women, respectively. The associations remained statistically significant after adjusting for diet, physical activity, BMI and cardiometabolic risk factors only among women.

\section{Comparison with the previous studies in China: CKD prevalence}

Reduced eGFR was observed among $8.1 \%$ of the participants. This is comparatively higher than that reported in previous studies in Chinese adults that used eGFR of less than $60 \mathrm{~mL} / \mathrm{min} / 1.73 \mathrm{~m}^{2}$ to indicate reduced renal function (i.e., 1.7 to $3.2 \%$ ) $[9,14,16,40,41]$. For example, Zhang et al. [14] reported that the prevalence was $1.7 \%$, using a nationally representative sample of Chinese adults ( $n=47,204$; mean age $=49.6$ years) conducted in 2009 and 2010, and Chen et al. [9] reported it to be 3.2\% among 6311 residents in Guangzhou (mean age $=51.6$ years). However, when we calculated the prevalence among participants aged 40 years or older for comparability, the prevalence of reduced renal function (10.6\%) fell between the ranges of those reported in previous research studying middle-aged and old people. For example, using China Health and Retirement Longitudinal Survey data in 2011 and 2012, Wang et al. [23] showed that reduced eGFR was reported among $11.5 \%$ of the participants. Zhang et al. [10] 
Table 3 Results of a multilevel logistic model to investigate the association between urbanization and reduced renal function among Chinese women (2009)

\begin{tabular}{|c|c|c|c|c|c|c|c|c|c|c|c|c|}
\hline & \multicolumn{3}{|c|}{ Model 1} & \multicolumn{3}{|c|}{ Model 2} & \multicolumn{3}{|c|}{ Model 3} & \multicolumn{3}{|c|}{ Model 4} \\
\hline & $\mathrm{OR}$ & $95 \% \mathrm{Cl}$ & $p$-value & $\mathrm{OR}$ & $95 \% \mathrm{Cl}$ & $p$-value & $\mathrm{OR}$ & $95 \% \mathrm{Cl}$ & $p$-value & $\mathrm{OR}$ & $95 \% \mathrm{Cl}$ & $p$-value \\
\hline Urbanization $^{a}$ & 1.35 & $1.11,1.62$ & 0.002 & 1.29 & $1.06,1.58$ & 0.011 & 1.29 & $1.06,1.57$ & 0.012 & 1.24 & $1.01,1.52$ & 0.041 \\
\hline \multicolumn{13}{|l|}{ Health-related behavior } \\
\hline Alcohol consumption $^{\text {b }}$ & & & & 0.75 & $0.42,1.35$ & 0.333 & 0.76 & $0.42,1.36$ & 0.349 & 0.74 & $0.41,1.35$ & 0.332 \\
\hline Total physical activity $^{c}$ & & & & 0.99 & $0.98,1.00$ & 0.296 & 0.99 & $0.98,1.00$ & 0.268 & 1.00 & $0.99,1.01$ & 0.444 \\
\hline Energy intake ${ }^{d}$ & & & & 0.91 & $0.61,1.36$ & 0.640 & 0.82 & $0.56,1.22$ & 0.335 & 0.92 & $0.61,1.39$ & 0.699 \\
\hline Protein intake $e^{e}$ & & & & 1.99 & $0.62,6.44$ & 0.250 & 0.95 & $0.33,2.76$ & 0.924 & 1.85 & $0.56,6.10$ & 0.311 \\
\hline Sodium intake & & & & 0.98 & $0.92,1.04$ & 0.452 & & & & 0.97 & $0.92,1.03$ & 0.382 \\
\hline Potassium intake & & & & 0.64 & $0.45,0.92$ & 0.017 & & & & 0.64 & $0.44,0.92$ & 0.016 \\
\hline Sodium-to-potassium ratio & & & & & & & 0.98 & $0.92,1.05$ & 0.624 & & & \\
\hline \multicolumn{13}{|l|}{ Cardiometabolic risk factors } \\
\hline Overweight/Obesity ${ }^{f}$ & & & & & & & & & & 0.89 & $0.67,1.18$ & 0.424 \\
\hline Hypertension $^{9}$ & & & & & & & & & & 1.34 & $1.01,1.78$ & 0.039 \\
\hline Diabetes Mellitus ${ }^{\mathrm{h}}$ & & & & & & & & & & 2.07 & $1.47,2.92$ & 0.000 \\
\hline High LDL ${ }^{i}$ & & & & & & & & & & 1.42 & $1.09,1.87$ & 0.010 \\
\hline
\end{tabular}

Models were adjusted for age (in years), educational attainment (primary education or less, junior high school, high school and attained further education) and household income

${ }^{\text {a }}$ Results are expressed per one-SD increase

${ }^{\mathrm{b}}$ The referent was those who drank less than once per month

${ }^{\mathrm{C}}$ Results are expressed per $10 \mathrm{METs}$ increase

${ }^{\mathrm{d}}$ Results are expressed per $1000 \mathrm{kcal}$ increase

Results are expressed per $100 \mathrm{~g}$ increase

${ }^{f}$ The referent was those whose body mass index was 24.0 or less

${ }^{9}$ Hypertension was defined by either systolic pressure $\geq 140 \mathrm{mmHg}$, diastolic pressure $\geq 90 \mathrm{mmHg}$ or self-reported antihypertensive medication

${ }^{h}$ Diabetes were defined by either hemoglobin $A 1 \mathrm{c} \geq 6.5 \%$ or fasting blood glucose $\geq 126 \mathrm{mg} / \mathrm{dL}$ or self-reported diagnosis of DM

'Higher LDL was defined by LDL $\geq 130 \mathrm{mg} / \mathrm{dL}$

Table 4 Results of multilevel logistic regression analyses using the 12 components of the urbanization index among Chinese participants (2009)

\begin{tabular}{|c|c|c|c|c|c|c|}
\hline \multirow[b]{2}{*}{ Urbanization components $^{\mathrm{a}}$} & \multicolumn{3}{|c|}{ Male participants } & \multicolumn{3}{|c|}{ Female participants } \\
\hline & $\mathrm{OR}$ & $95 \% \mathrm{Cl}$ & $p$-value & $\mathrm{OR}$ & $95 \% \mathrm{Cl}$ & $p$-value \\
\hline Population Density & 1.13 & $0.88,1.46$ & 0.330 & 1.07 & $0.87,1.32$ & 0.498 \\
\hline Economic Component & 0.90 & $0.64,1.27$ & 0.551 & 0.99 & $0.75,1.31$ & 0.960 \\
\hline Traditional Market & 1.21 & $0.93,1.58$ & 0.161 & 1.27 & $1.01,1.58$ & 0.036 \\
\hline Modern Market & 1.08 & $0.80,1.47$ & 0.606 & 1.23 & $0.95,1.59$ & 0.117 \\
\hline Transportation & 0.90 & $0.71,1.15$ & 0.398 & 1.09 & $0.90,1.32$ & 0.391 \\
\hline Sanitation & 0.90 & $0.61,1.32$ & 0.576 & 0.83 & $0.60,1.15$ & 0.272 \\
\hline Communications & 0.85 & $0.63,1.13$ & 0.262 & 0.75 & $0.59,0.95$ & 0.017 \\
\hline Housing & 1.51 & $1.01,2.28$ & 0.047 & 1.39 & $1.01,1.93$ & 0.046 \\
\hline Education & 1.05 & $0.77,1.42$ & 0.762 & 1.17 & $0.90,1.52$ & 0.252 \\
\hline Diversity & 0.84 & $0.64,1.10$ & 0.203 & 0.81 & $0.64,1.01$ & 0.064 \\
\hline Health & 0.87 & $0.69,1.11$ & 0.261 & 0.80 & $0.66,0.98$ & 0.031 \\
\hline Social Service & 1.16 & $0.92,1.48$ & 0.217 & 1.04 & $0.85,1.28$ & 0.689 \\
\hline
\end{tabular}

Models were adjusted for age (in years), educational attainment (primary education or less, junior high school, high school and attained further education), household income, health-related behavior and cardiometabolic risk factors

${ }^{\mathrm{a}}$ Results are expressed per one-SD increase 
reported the prevalence of reduced renal function among those who lived in Beijing and were aged 40 years or older to be $5.2 \%$. Chen et al. [42] showed the prevalence of reduced eGFR to be $2.5 \%$ among Chinese participants aged 35 to 74 years in 2000 to 2004. Li et al. [11] studied 2310 middle- and old-aged adults in Beijing and reported CKD and reduced eGFR in 12.9 and $4.9 \%$ of the population, respectively. Shan et al. [43] studied CKD in 4156 participants aged 40 years or older living in four major cities in Henan, finding reduced eGFR in $1.53 \%$ of the participants. The prevalence of reduced renal function we report in this study was somewhat high but still within the reported range.

The association between community-level variables with CKD We found that living in a more urbanized community were associated with higher odds of having reduced renal function. This is consistent with Wang et al. [23] showing that reduced eGFR prevalence was higher in urban (13.0\%) compared with rural (10.0\%) Chinese adults. However, other studies have not reported such an association [42] perhaps because these other studies were conducted earlier in the process of urbanization when its impact on reduced renal function might have been yet to appear. For example, using data from 15,540 Chinese general population aged 35 to 74 years collected in 2000 and 2001, Chen et al. [42] showed that there was no statistically significant difference in CKD prevalence between those who lived in urban $(2.6 \%)$ and rural $(2.5 \%)$ areas. Second, as previously mentioned, the crude, dichotomous classification of places as urban or rural might have blurred the association between urbanization and CKD. Zhang et al. [14] showed that the degree of economic development (operationalized with gross domestic product tertiles) was positively associated with albuminuria (one of the indicators of renal damage) only in rural communities. This finding may stem from the fact that among rural communities, urbanization is more straightforward to measure and could be evaluated with gross economic product only. In urban areas, economic development may need to be classified using a more nuanced approach than used in the Zhang study.

After adjusting for lifestyle-related factors and cardiometabolic risk factors (i.e., hypertension, DM and high LDL cholesterol), the association between urbanization and the odds of reduced renal function was attenuated in both sexes, which suggests that these risk factors underlie the association between urbanization and CKD. However, given that the association between urbanization and reduced renal function remained statistically significant particularly in women, other aspects of living in more urbanized environments $[6,44]$ may be associated with reduced renal function, particularly in women.
In this context, the analysis incorporating the $12 \mathrm{com}$ ponents of the urbanization index may help identify the aspects which were associated with reduced renal function. The associations observed in the analysis suggest that the impact of urbanization on renal function might vary depending on aspects of urbanization we focus on. As most of the information included in each component did not seem to have direct effects on renal function [25], the associations observed in this study might have been due to some other factors associated with the aspect of urbanization process. For example, the housing component consists of information on availability of electricity, indoor tap water, flush toilet and cooking gas while the traditional market component consists of information on distance to the market, the number of days of operation for eight types of market, none of which have been previously shown to be linked directly with chronic kidney disease; the two components which were found to be associated with lower odds of reduced renal function in women also did not seem to directly affect renal function. However, future research can pay attention to these aspects of urbanization to elucidate exact mechanisms linking urbanization and reduced renal function while these single elements of urbanization may not fully represent the sum total effects of urbanization.

The association between individual-level variables and CKD Alcohol consumption was inversely associated with the prevalence of reduced renal function in this study; reverse causality might be the case (i.e., old participants who had reduced renal function were also the ones who did not drink alcohol). In contrast, other researchers have found a positive association between alcohol consumption and CKD risk [19], while others have reported an inverse association [45-47]. Although health risks associated with alcohol consumption are well recognized [48], alcohol consumption might be protective for renal function. While some studies [9, 10, 17-19] suggested a higher risk of CKD among smokers with some exceptions [16], we did not find a statistically significant difference between smokers and non-smokers. While this insignificance might have been due to lack of information on past smoking status, future study is needed to account for second-hand smoking, as more than half of men in China are smokers, which might influence others irrespective of their own smoking status. Evidence suggests that second hand smoking affects proteinuria in children with CKD [49].

Those men who engaged in higher physical activity had lower odds of reduced renal function, but this was attenuated after adjusting for cardiometabolic risk factors. As previous studies also showed an association between physical inactivity and CKD [17, 18], physical 
activity may influence renal function through cardiometabolic risk factors. We did not find a statistical association between sodium intake and reduced renal function in this study. A systematic review by Smyth et al. [50] reported conflicting results in relation to sodium intake and suggested that both high intake and low intake may associate with higher risk of adverse renal outcomes compare with moderate intake; we did not find such an association when we used a squared term of sodium intake (data not shown). While there is limited study on the association between dietary potassium and reduced renal function, research on other health outcomes has produced similar findings to the association observed in women in our study; Khaw et al. [51] reported that low potassium intake was associated with higher risk of stroke-associated mortality in women (relative risk $[\mathrm{RR}]=4.8, p=0.01)$ and that this association was less pronounced in men $(\mathrm{RR}=2.6, p=0.16)$.

\section{Strengths and limitations}

There are some limitations to this study. First, we did not have information on albuminuria as we did not collect urinary samples. Albuminuria is used to diagnose CKD in clinical settings and this could have led us to fail to identify some of those who had CKD. Also, creatinine concentrations were only measured once for each participant while CKD is generally defined as the presence of either kidney damage or decreased kidney function for more than three months [34]. Second, the crosssectional design of the study prevented us from making causal inference. This might be especially important in relation to the association of alcohol consumption, total physical activity, and potassium intake with reduced renal function, which were shown to be associated with reduced renal function but which also could have been due to reverse causality. In addition, the effect of smoking status was investigated only based on current smoking status in this study. This might have been problematic as cadmium, one of the important sources of which has been reported to be smoking in China, may have accumulated throughout one's life and eventually caused renal damage [52].

Despite the limitations described above, this study has strengths which extend the previous studies on the renal function in the developing countries. Specifically, we found that the prevalence of reduced renal function increased along with urbanization, independent of other cardiometabolic risk factors. This should be taken into consideration by public health officers and researchers working in developing countries where economic development and urbanization are rapidly taking place. Future studies are needed to identify biological pathways, which may link urbanization and the occurrence of reduced renal function. It should also be mentioned that our multidimensional measure of urbanization captures heterogeneity in a variety of services and infrastructure within and between high- and low-urbanized areas. When we decomposed urbanization into its components we saw the significant associations with specific elements of urbanization, but these single associations may not have fully represented the sum total effects of urbanization on renal function.

\section{Conclusion}

In Chinese adults, we found that living in an urban environment was associated with higher odds of reduced renal function, independently of behavioral and cardiometabolic risk factors which have also been shown to increase along with urbanization process.

\section{Additional file}

Additional file 1: Table S1. Characteristics of the study participants in China Health and Nutrition Survey (2009), stratified by the degree of urbanization. It contains basic characteristics of the study participants, stratified by the degree of urbanization. (DOCX $25 \mathrm{~kb}$ )

\section{Abbreviations \\ BMI: Body mass index; CHNS: China Health and Nutrition Survey; CKD: Chronic kidney disease; CKD-EPl: Chronic kidney disease-epidemiology equation; DM: Diabetes mellitus; eGFR: Estimated glomerular filtration rate; LDL: Low-density lipoprotein cholesterol; MET: Metabolic equivalent; OR: Odds ratio; RR: Relative risk; Scr: Serum creatinine concentration; SD: Standard deviation; SES: Socioeconomic status}

\section{Acknowledgements}

The authors thank the National Institute for Nutrition and Health, Chinese Center for Disease Control and Prevention, the Carolina Population Center, the UNC-CH and all the people involved in the China Health and Nutrition Survey.

\section{Funding}

This work was supported by the National Institutes of Health, National Heart, Lung, Blood Institute (R01-HL108427, R01-DK104371). This research uses data from the China Health and Nutrition Survey, funded by the Eunice Kennedy Shriver National Institute of Child Health and Human Development (NICHD) (R01-HD30880), although no direct support was received from grant for this analysis. We also are grateful to the Carolina Population Center (P2C HD050924) for general support. The funders had no role in the design and analysis of the study or in the writing of this article. Y.I. is financially supported by the Nippon Foundation International Fellowship program.

Availability of data and materials

Data available at: http://www.cpc.unc.edu/projects/china/

\section{Authors' contributions}

All authors contributed to conception, design, and interpretation of data, YI contributed to data analysis, PGL contributed to the acquisition of data, YI drafted the manuscript, $A G H, A H H, A L T, M M$ and $P G L$ contributed to critical revision of the manuscript. $Y$ I and $P G L$ had full access to all the data in the study and take responsibility for the integrity of the data and the accuracy of the data analysis. All authors have read and approved the final manuscript.

\section{Competing interests}

The authors declare that they have no competing interests.

Consent for publication

Not Applicable. 


\section{Ethics approval and consent to participate}

The study was approved by the Institutional Review Board at the University of North Carolina at Chapel Hill, the China-Japan Friendship Hospital and the Chinese Center for Disease Control and Prevention's National Institute for Nutrition and Health. Subjects gave informed consent for participation. The work presented in this paper was approved by the UNC IRB under a larger project focusing on urbanization and health. Furthermore, the China Health and Nutrition Survey data are publicly available and supported by R01-HD30880

\section{Publisher's Note}

Springer Nature remains neutral with regard to jurisdictional claims in published maps and institutional affiliations.

\section{Author details}

${ }^{1}$ Carolina Population Center, The University of North Carolina at Chapel Hill, Chapel Hill, NC 27516, USA. ²Department of Biostatistics, Gillings School of Global Public Health, The University of North Carolina at Chapel Hill, Chape Hill, NC 27599, USA. ${ }^{3}$ Department of Anthropology, The University of North Carolina at Chapel Hill, Chapel Hill, NC 27599, USA. ${ }^{4}$ Department of Nutrition, Gillings School of Global Public Health, The University of North Carolina at Chapel Hill, Chapel Hill, NC 27599, USA

Received: 31 December 2016 Accepted: 8 May 2017

Published online: 15 May 2017

\section{References}

1. Keith DS, Nichols GA, Gullion CM, Brown JB, Smith DH. Longitudinal followup and outcomes among a population with chronic kidney disease in a large managed care organization. Arch Intern Med. 2004;164(6):659-63.

2. Go AS, Chertow GM, Fan D, McCulloch CE, Hsu C-Y. Chronic kidney disease and the risks of death, cardiovascular events, and hospitalization. N Engl J Med. 2004;351(13):1296-305.

3. Smyth A, Glynn LG, Murphy AW, Mulqueen J, Canavan M, Reddan DN, O'Donnell M. Mild chronic kidney disease and functional impairment in community-dwelling older adults. Age Ageing. 2013;42(4):488-94.

4. Lin C-Y, Lin L-Y, Kuo H-K, Lin J-W. Chronic kidney disease, atherosclerosis, and cognitive and physical function in the geriatric group of the National Health and Nutrition Survey 1999-2002. Atherosclerosis. 2009;202(1):312-9.

5. Lozano R, Naghavi M, Foreman K, Lim S, Shibuya K, Aboyans V, Abraham J, Adair T, Aggarwal R, Ahn SY. Global and regional mortality from 235 causes of death for 20 age groups in 1990 and 2010: a systematic analysis for the Global Burden of Disease Study 2010. Lancet. 2013;380(9859):2095-128.

6. Stanifer JW, Muiru A, Jafar TH, Patel UD. Chronic kidney disease in low- and middle-income countries. Nephrol Dial Transplant. 2016;31(6):868-74.

7. Jha V, Garcia-Garcia G, Iseki K, Li Z, Naicker S, Plattner B, Saran R, Wang AYM, Yang CW. Chronic kidney disease: global dimension and perspectives. Lancet. 2013:382(9888):260-72.

8. Pan L, Ma R, Wu Y, Feng L, Song YS, Ye XD, Zhang YH, Yang ZH, Liao YH. Prevalence and risk factors associated with chronic kidney disease in a Zhuang ethnic minority area in China. Nephrology. 2015;20(11):807-13.

9. Chen W, Chen W, Wang H, Dong X, Liu Q, Mao H, Tan J, Lin J, Zhou F, Luo $\mathrm{N}$, et al. Prevalence and risk factors associated with chronic kidney disease in an adult population from southern China. Nephrol Dial Transplant. 2009; 24(4):1205-12

10. Zhang LX, Zuo L, Xu GB, Wang F, Wang M, Wang SY, Lv JC, Liu LS, Wang HY. Community-based screening for chronic kidney disease among populations older than 40 years in Beijing. Nephrol Dial Transpl. 2007;22(4):1093-9.

11. Li ZY, Xu GB, Xia TA, Wang HY. Prevalence of chronic kidney disease in a middle and old-aged population of Beijing. Clin Chim Acta. 2006;366(1-2): 209-15.

12. Kaze FF, Meto DT, Halle MP, Ngogang J, Kengne AP. Prevalence and determinants of chronic kidney disease in rural and urban Cameroonians: a cross-sectional study. BMC Nephrol. 2015;16:117.

13. Chen W, Liu QH, Wang H, Chen WQ, Johnson RJ, Dong XQ, Li HY, Ba S, Tan $J Q$, Luo N, et al. Prevalence and risk factors of chronic kidney disease: a population study in the Tibetan population. Nephrol Dial Transpl. 2011; 26(5):1592-9.

14. Zhang L, Wang F, Wang L, Wang W, Liu B, Liu J, Chen M, He Q, Liao Y, Yu X. Prevalence of chronic kidney disease in China: a cross-sectional survey. Lancet. 2012;379(9818):815-22.
15. Zhang QL, Rothenbacher D. Prevalence of chronic kidney disease in population-based studies: Systematic review. BMC Public Health. 2008:8:117.

16. Wang F, Ye P, Luo L, Xiao W, Wu H. Association of risk factors for cardiovascular disease and glomerular filtration rate: a community-based study of 4,925 adults in Beijing. Nephrol Dial Transplant. 2010;25(12):3924-31.

17. Stengel B, Tarver-Carr ME, Powe NR, Eberhardt MS, Brancati FL. Lifestyle factors, obesity and the risk of chronic kidney disease. Epidemiology. 2003; 14(4):479-87.

18. Hallan S, de Mutsert R, Carlsen S, Dekker FW, Aasarod K, Holmen J. Obesity, smoking, and physical inactivity as risk factors for CKD: are men more vulnerable? Am J Kidney Dis. 2006;47(3):396-405.

19. Shankar A, Klein R, Klein BEK. The association among smoking, heavy drinking, and chronic kidney disease. Am J Epidemiol. 2006;164(3):263-71.

20. Fored CM, Ejerblad E, Fryzek JP, Lambe M, Lindblad P, Nyren O, Elinder CG. Socio-economic status and chronic renal failure: a population-based casecontrol study in Sweden. Nephrol Dial Transplant. 2003;18(1):82-8.

21. Merkin SS, Roux AVD, Coresh J, Fried LF, Jackson SA, Powe NR. Individual and neighborhood socioeconomic status and progressive chronic kidney disease in an elderly population: The Cardiovascular Health Study. Soc Sci Med. 2007;65(4):809-21.

22. Bello AK, Peters J, Rigby J, Rahman AA, El Nahas M. Socioeconomic status and chronic kidney disease at presentation to a renal service in the United Kingdom. Clin J Am Soc Nephrol. 2008:3(5):1316-23.

23. Wang S, Chen R, Liu Q, Shu Z, Zhan S, Li L. Prevalence, awareness and treatment of chronic kidney disease among middle-aged and elderly: The China Health and Retirement Longitudinal Study. Nephrology. 2015;20(7): 474-84.

24. Yu X, Yang X. Peritoneal dialysis in China: meeting the challenge of chronic kidney failure. Am J Kidney Dis. 2015;65(1):147-51.

25. Jones-Smith JC, Popkin BM. Understanding community context and adult health changes in China: Development of an urbanicity scale. Soc Sci Med. 2010;71(8):1436-46.

26. Merlo J, Yang M, Chaix B, Lynch J, Rastam L. A brief conceptual tutorial on multilevel analysis in social epidemiology: investigating contextual phenomena in different groups of people. J Epidemiol Community Health. 2005:59(9):729-36.

27. National Bureau of Statistics of China. China Statistical Yearbook. Beijing: China Statistics Press; 2007

28. Chen C. Nutrition status of the Chinese people. Biomed Environ Sci. 1996; 9(2-3):81-92.

29. Ge K, Zhai F, Yan $H$. The dietary and nutritional status of Chinese population (1992 National Nutrition Survey). Beijing: People's Medical Publishing House; 1996. p. 442-6.

30. Wang L. Report of China nationwide nutrition and health survey 2002 (1): summary report. Beijing: People's Medical Publishing House; 2005. p. 18-45.

31. Popkin BM. The implications of the nutrition transition for obesity in the developing world. In: Crawford D et al. (eds.) Obesity epidemiology: from aetiology to public health. Oxford: Oxford University Press; 2010.

32. Pei $X$, Yang W, Wang S, Zhu B, Wu J, Zhu J, Zhao W. Using mathematical algorithms to modify glomerular filtration rate estimation equations. PLoS One. 2013;8(3):e57852

33. Ye X, Liu X, Song D, Zhang X, Zhu B, Wei L, Pei X, Wu J, Lou T, Zhao W. Estimating glomerular filtration rate by serum creatinine or/and cystatin C equations: an analysis of multi-centre Chinese subjects. Nephrology. 2016; 21(5):372-8.

34. Levey AS, Coresh J, Balk E, Kausz AT, Levin A, Steffes MW, Hogg RJ, Perrone RD, Lau J, Eknoyan G. National Kidney Foundation practice guidelines for chronic kidney disease: evaluation, classification, and stratification. Ann Intern Med. 2003;139(2):137-47.

35. Yang Y. Chinese food composition table 2004. Beijing: Peking University Medical Press; 2005

36. Yao MJ, McCrory MA, Ma GS, Tucker KL, Gao SJ, Fuss P, Roberts SB. Relative influence of diet and physical activity on body composition in urban Chinese adults. Am J Clin Nutr. 2003;77(6):1409-16.

37. Du SF, Neiman A, Wang HJ, Zhang B, Popkin BM. Understanding the patterns and trends of potassium intake and sodium/potassium ratio in China, 1991-2009. FASEB J. 2012:26

38. Zhou B. Effect of body mass index on all-cause mortality and incidence of cardiovascular diseases-report for meta-analysis of prospective studies open optimal cut-off points of body mass index in Chinese adults. Biomed Environ Sci. 2002;15(3):245-52. 
39. Alberti KGMM, Zimmet P, Shaw J. Metabolic syndrome-a new world-wide definition. A Consensus Statement from the International Diabetes Federation. Diabetic Medicine. 2006;23(5):469-80.

40. Xu R, Zhang LX, Zhang PH, Wang F, Zuo L, Wang HY. Gender differences in age-related decline in glomerular filtration rates in healthy people and chronic kidney disease patients. BMC Nephrol. 2010;11:20.

41. Hong D, Zhang Y, Gao B, Wang J, Li G, Wang L, Zhang L, China National Survey of CKDWG. metabolic syndrome without diabetes or hypertension still necessitates early screening for chronic kidney disease: information from a Chinese national cross-sectional study. PLoS One. 2015;10(7):e0132220.

42. Chen J, Wildman RP, Gu D, Kusek JW, Spruill M, Reynolds K, Liu D, Hamm LL, Whelton PK, He J. Prevalence of decreased kidney function in Chinese adults aged 35 to 74 years. Kidney Int. 2005;68(6):2837-45.

43. Shan Y, Zhang Q, Liu Z, Hu X, Liu D. Prevalence and risk factors associated with chronic kidney disease in adults over 40 years: a population study from Central China. Nephrology. 2010;15(3):354-61.

44. Mehta AJ, Zanobetti A, Bind MAC, Kloog I, Koutrakis P, Sparrow D, Vokonas PS, Schwartz JD. Long-term exposure to ambient fine particulate matter and renal function in older men: the veterans administration normative aging study. Environ Health Perspect. 2016;124(9):1353-60.

45. White SL, Polkinghorne KR, Cass A, Shaw JE, Atkins RC, Chadban SJ. Alcohol consumption and 5-year onset of chronic kidney disease: the AusDiab study. Nephrol Dial Transpl. 2009;24(8):2464-72.

46. Reynolds K, Gu D, Chen J, Tang X, Yau CL, Yu L, Chen CS, Wu X, Hamm LL, $\mathrm{He}$ J. Alcohol consumption and the risk of end-stage renal disease among Chinese men. Kidney Int. 2008;73(7):870-6.

47. Schaeffner ES, Kurth T, De Jong PE, Glynn RJ, Buring JE, Gaziano JM. Alcohol consumption and the risk of renal dysfunctskion in apparently healthy men. Arch Intern Med. 2005;165(9):1048-53.

48. Room R, Babor T, Rehm J. Alcohol and public health. Lancet. 2005;365(9458): 519-30.

49. Omoloja A, Jerry-Fluker J, Ng DK, Abraham AG, Furth S, Warady BA, Mitsnefes $M$. Secondhand smoke exposure is associated with proteinuria in children with chronic kidney disease. Pediatr Nephrol. 2013;28(8):1243-51.

50. Smyth A, O'Donnell MJ, Yusuf S, Clase CM, Teo KK, Canavan M, Reddan DN, Mann JFE. Sodium intake and renal outcomes: a systematic review. Am J Hypertens. 2014;27(10):1277-84.

51. Khaw KT, Barrettconnor E. Dietary potassium and stroke-associated mortality - a 12-year prospective population study. N Engl J Med. 1987;316(5):235-40.

52. O'Connor RJ, Li Q, Stephens WE, Hammond D, Elton-Marshall T, Cummings KM, Giovino GA, Fong GT. Cigarettes sold in China: design, emissions and metals. Tob Control. 2010;19(Supp 2):47-53.

\section{Submit your next manuscript to BioMed Central and we will help you at every step:}

- We accept pre-submission inquiries

- Our selector tool helps you to find the most relevant journal

- We provide round the clock customer support

- Convenient online submission

- Thorough peer review

- Inclusion in PubMed and all major indexing services

- Maximum visibility for your research

Submit your manuscript at www.biomedcentral.com/submit 